\title{
Role of ADAMTS16 metalloproteinase in pathogenesis of cryptorchidism
}

Joanna Gerszon ${ }^{1}$, Jacek Kabziński ${ }^{1}$, Piotr Kucharski², Ireneusz Majsterek ${ }^{1}$, Jerzy K. Niedzielski²

1Department of Clinical Chemistry and Biochemistry, Medical University of Lodz, Poland

${ }^{2}$ Department of Pediatric Surgery and Urology, University Pediatric Centre, Central Hospital of Medical University of Lodz, Poland

Submitted: 10 June 2020

Accepted: 3 September 2020

Arch Med Sci

DOI: https://doi.org/10.5114/aoms.2020.10064

Copyright $\odot 2020$ Termedia \& Banach

\begin{abstract}
Introduction: The etiology of cryptorchidism is still not fully elucidated, but several hypotheses have been proposed. One of the latest concerns is the involvement of metalloproteinase ADAMTS16 in testis descent. The aim of this study was to evaluate both expression and occurrence of selected polymorphisms of metalloproteinase ADAMTS16 in patients diagnosed with cryptorchidism.
\end{abstract}

Material and methods: The study group consisted of 158 boys (mean age: $4.1 \pm 2.04$ years) who underwent surgery due to undescended testis. Tissue samples from patients with cryptorchidism were obtained from the cremaster muscle, gubernaculum and hernial sac. The reference group consisted of 123 age-related subjects (mean age: $4.1 \pm 2.41$ years) who had no cryptorchidism and underwent surgery for other reasons. Tissue samples from controls were obtained from the cremaster muscle and hernial sac.

Results: The obtained data indicate that patients with undescended testis have significantly lower expression of Adamts16, especially in the gubernaculum. We also demonstrated a tendency that Adamts 16 expression depends on the age of patients; the older the patient was, the higher was the observed expression of Adamts16. These studies also established that polymorphisms rs16875319, rs16875122, and rs58353460 in the Adamts16 gene are not a major determinant to develop cryptorchidism while rs16875054 is associated with increased risk.

Conclusions: These studies highlight ADAMTS16 involvement in cryptorchidism and confirm data obtained in animal models.

Key words: metalloproteinases, cryptorchidism, ADAMTS16.

\section{Introduction}

Cryptorchidism is the absence of one or both testes from the scrotum. It is the most common congenital anomaly of the male gonads, affecting $1.0-4.6 \%$ of full-term and $1.1-45 \%$ of preterm neonates. Although the majority of testes descend spontaneously within the first months of life, nearly $1.0 \%$ of all full-term male infants still have undescended testes (UDT) at 6 months of age, necessitating surgical intervention [1]. Cryptorchidism in most cases occurs without comorbidities and is considered an occasional birth defect. Various factors that can cause the disease are taken into account, among which special attention is paid to hormo-

\author{
Corresponding author: \\ Prof. Jerzy K. Niedzielski \\ Department of \\ Pediatric Surgery \\ and Urology \\ University Pediatric \\ Centre \\ Central Hospital \\ of Medical University \\ of Lodz, Poland \\ Phone: +48 502133992 \\ E-mail: jniedzielski@orange.pl
}


nal factors, genetic factors, maternal health and environmental factors. At present, the combination of all these elements is primarily considered [2, 3]. Furthermore, cryptorchidism is commonly observed in several dysmorphic syndromes, some neuromuscular disorders and also in some inherited metabolic diseases. Despite extensive research establishing an unequivocal basis of the disease, the probable causes are multi-component factors, making cryptorchidism a disease of complex etiology $[4,5]$.

Bilateral UDT increases the risk of being infertile six-fold compared with unilateral UDT or with the general healthy male population. Approximately $10 \%$ of infertile men have a history of cryptorchidism and orchidopexy. The significance of this problem has been noted, but until now, the exact causes and development of this defect at the molecular level have not been fully elucidated [1].

The latest studies indicated that one factor amplifying the occurrence of cryptorchidism is the absence of the metalloproteinase ADAMTS16 (a Disintegrin And Metalloproteinase with ThromboSpondin motifs16) [6]. In vivo studies have already highlighted the importance of matrix metalloproteinases (MMPs), which modulate intra- and extracellular pathways and networks by proteolytic processing of various biomolecules. Due to their activity they are functionally implicated in the regulation of various physiological (such as embryogenesis, apoptosis, cell migration, growth and remodeling of connective tissue and wound healing) [7]; and in pathological processes (inflammation, neoplasm, autoimmune and neurological diseases or atherosclerosis) [8-13]. Therefore, metalloproteinase activity is tightly controlled by epigenetic, transcriptional, and post-transcriptional gene expression regulation, post-translational modifications (PTMs), proteolytic activation, and interactions with specific endogenous inhibitors (tissue inhibitors of metalloproteinases - TIMPS) [14]. Apart from TIMPs, various unspecific inhibiting factors have been found such as $\alpha_{2}$-macroglobulin, $\beta$-amyloid precursor protein and heparin [15].

ADAMTS forms a family of 19 proteins which display diverse, tissue-dependent roles. Mostly they play an important role in inter-cellular interactions, adhesion, cell fusion and exfoliation of proteins from the cell surface. In the exfoliation process, many of the integral membrane proteins are released and form soluble, physiologically active proteins, modulating the surrounding environment [16]. They take part in processes such as extracellular matrix turnover, melanoblast development, interdigital web regression, blood coagulation, ovulation, etc. [14, 17-19].

Human genetic studies have revealed potential associations of the activity/presence of ADAMTS and different malfunctions, inter alia disorders and birth defects resulting from Adamts2, Adamts3, Adamts10, Adamts13, Adamts17, Adamts20, Adamtsl2 and Adamts/4 mutations [14].

Recently also ADAMTS16 was described as an important factor inter alia in morphogenesis, with special emphasis on its role in rat testis development [6]. However, until now there are no data regarding the role of ADAMTS16 in testicular descent in humans.

Therefore, the aim of this study was to evaluate Adamts16 expression in patients with diagnosed cryptorchidism. Also considering the hypothesis described above and the possible modifying effect conferred by polymorphisms, the objective of this study was to evaluate the frequency of the polymorphisms rs16875319, rs16875054, rs16875122, and rs58353460 in the Adamts16 gene in patients with UDT, and to correlate the frequency of the different polymorphisms with the incidence of cryptorchidism.

\section{Material and methods}

\section{Material}

The study group consisted of 158 unrelated boys (mean age: $4.1 \pm 2.04$ years) who underwent surgery due to unilateral UDT. The reference group consisted of 123 age-related subjects (mean age: $4.1 \pm 2.41$ years) who had no cryptorchidism and underwent surgery for other reasons, mainly due to inguinal hernia. All patients were operated on in the Department of Pediatric Surgery and Urology, Medical University of Lodz, between January 2017 and June 2019.

Experimental material, i.e. DNA, was isolated from peripheral blood samples obtained from patients of both the study and the reference group before surgery.

Tissue samples from 42 patients with UDT (mean age: $4.07 \pm 2.96$ years) were obtained from the cremaster muscle, gubernaculum and hernial sac (126 samples) during orchidopexy. The inclusion criterion was diagnosed cryptorchidism and exclusion criteria were inherited arterial hypertension, and esophageal squamous cell carcinoma in the past family history.

Tissue samples from 21 control individuals (mean age: $4.13 \pm 2.86$ years) were obtained from the cremaster muscle and hernial sac (42 samples). The samples were collected in the Department of Clinical Chemistry and Biochemistry, Medical University of Lodz.

The study was approved by the Bioethics Committee of the Medical University of Lodz (No. RNN/162/09/KE of 17.02.2009 with modification $\mathrm{KE} / 256 / 18$ of 13.03 .2018 and RNN/102/17/KE of 11.04.2017). 


\section{Methods}

Genomic DNA was isolated from blood samples using the QIAamp DNA Blood Mini Kit for isolation of high-molecular-weight DNA (Qiagen, Chatsworth, CA, USA).

The reaction was set up according to the TaqMan technology manual. In general, 100 ng of genomic DNA, TaqMan Genotyping Master Mix (Applied Biosystems), and TaqMan probes (catalog no. 4351379; SNP IDs: rs16875319, rs16875054, rs16875122, and rs58353460) were mixed and subjected to PCR reaction performed in CFX96 Touch Real-Time PCR (Bio-Rad) under the following conditions: $95^{\circ} \mathrm{C}$ for 10 min for polymerase activation, followed by 50 cycles including $95^{\circ} \mathrm{C}$ for $15 \mathrm{~s}$ and $60^{\circ} \mathrm{C}$ for $1 \mathrm{~min}$.

\section{Total RNA extraction and quantitative} real-time polymerase chain reaction (PCR)

Total RNA was extracted with the RNAqueous Total RNA Isolation Kit from collected tissue and reverse transcribed into cDNA using a RevertAid First Strand CDNA Synthesis Kit according to the manufacturer's protocol. We used 100 ng of RNA and performed 40 repetitions.

Quantitative real-time PCR was performed using an CFX96 Touch Real-Time PCR (Bio-Rad). The reaction mix $(12 \mu \mathrm{l})$ contained $0.2 \mathrm{nmol}$ of forward and reverse primer, cDNA template, water and SYBR Green PCR Master Mix. Reactions were incubated at $95^{\circ} \mathrm{C}$ for $10 \mathrm{~min}$, followed by 40 cycles of $95^{\circ} \mathrm{C}$ for $15 \mathrm{~s}$ and $56^{\circ} \mathrm{C}$ for $1 \mathrm{~min}$. The following gene-specific primers were used: Adamts16 f: ACGTACTGTACAAGAGATCC, r: ATGTATTTCTTGCGTCTTCC. Gene expression levels were normalized to the level of Gapdh using the following primers: f: ACAGTTGCCATGTAGACC and r: TTGAGCACAGGGTACTTTA.

\section{Statistical analysis}

The number of obtained genotypes was compared with the expected value under the HardyWeinberg law. The significance of differences between allele frequencies and genotypes for individual groups was assessed using the $\chi^{2}$ test. The risk of occurrence of the event was assessed by means of multivariate regression analysis (odds ratio - OR) with an appropriate confidence interval (95\% confidence interval $-95 \% \mathrm{Cl}$.

The significance of differences in Adamts16 expression in controls and patients with cryptorchidism was assessed by Mann-Whitney $U$ test. The criterion for statistical significance was set at $p<0.05$.

\section{Results}

As the latest studies on animal model indicated that Adamts16 is a critical gene required for the normal functioning of the genitourinary system, we decided to evaluate Adamts16 expression in patients diagnosed with cryptorchidism in three types of paratesticular tissues: cremaster muscle, gubernaculum testis, and hernial sac. The obtained results indicate that the level of Adamts16 mRNA in both cremaster muscle and gubernaculum testis in patients with cryptorchidism is lower in comparison to the controls (Figures $1 \mathrm{~A}-\mathrm{C}$ ). The most statistically considerable changes differences (the lowest expression) were observed in gubernaculum. As most control samples were obtained from the hernial sac, we also determined the level of Adamts16 mRNA in this tissue. The expression of Adamts16 was insignificantly lower in the hernial sac in patients with cryptorchidism in comparison to the controls (Figure $1 \mathrm{C}$ ). Taking into consideration the age of examined patients, the observed expression of Adamts16 was significantly higher in older boys (Figures $2 \mathrm{~A}, \mathrm{~B}$ ).

These studies suggested that deficiency of mRNA Adamts16 might be linked with occurrence of cryptorchidism. For that reason, in the next stage of our research we evaluated the influence of the presence of selected polymorphisms within the tested gene on the incidence of cryptorchidism.

Table I presents an analysis of the distribution of rs16875054 A/G polymorphism variants of the Adamts16 gene and its correlation with the modulation of the risk of cryptorchidism. The HardyWeinberg $(\mathrm{HW}) \chi^{2}$ analysis revealed that in the study group $\left(\chi^{2}=96.21 ; p<0.05\right)$ and in the control group $\left(\chi^{2}=30.27 ; p<0.05\right)$ genotype distribution of Adamts16 (rs16875054) gene polymorphism is not in the Hardy-Weinberg equilibrium. The frequencies of $A$ and $G$ alleles were respectively $13 \%$ and $87 \%$ in the study group and $6 \%$ and $94 \%$ in the control group, whereas the genotype distribution was $84 \%$ for GG, $5 \%$ for $A / G$ and $11 \%$ for $A A$ for cryptorchidism patients and $91 \%$ for GG, 6\% for $A / G$ and $3 \%$ for $A A$ for the controls. The obtained results indicate a relationship between the A/A genotype as well as the $A$ allele and the incidence of cryptorchidism. According to the calculated odds ratio, the homozygous $\mathrm{A} / \mathrm{A}$ variant $(\mathrm{OR}=3.4831,95 \% \mathrm{Cl}$ : $1.1384-10.6566)$ as well as the A allele $(O R=2.2993$, 95\% Cl: 1.2426-4.2544) are associated with more frequent occurrence of cryptorchidism.

Table II presents an analysis of the distribution of rs16875319 G/T polymorphism variants of the Adamts16 gene and its correlation with the modulation of the risk of cryptorchidism. Genotype distribution of Adamts16 (rs16875319) polymorphism showed no deviation from the Hardy-Weinberg equilibrium in the study group $\left(\chi^{2}=2.61 ; p=0.106\right)$ or in the control group $\left(\chi^{2}=0.073 ; p=0.787\right)$. The frequencies of $\mathrm{T}$ and $\mathrm{G}$ alleles were $82 \%$ and $18 \%$ in the examined group of patients and $83 \%$ and $17 \%$ in 

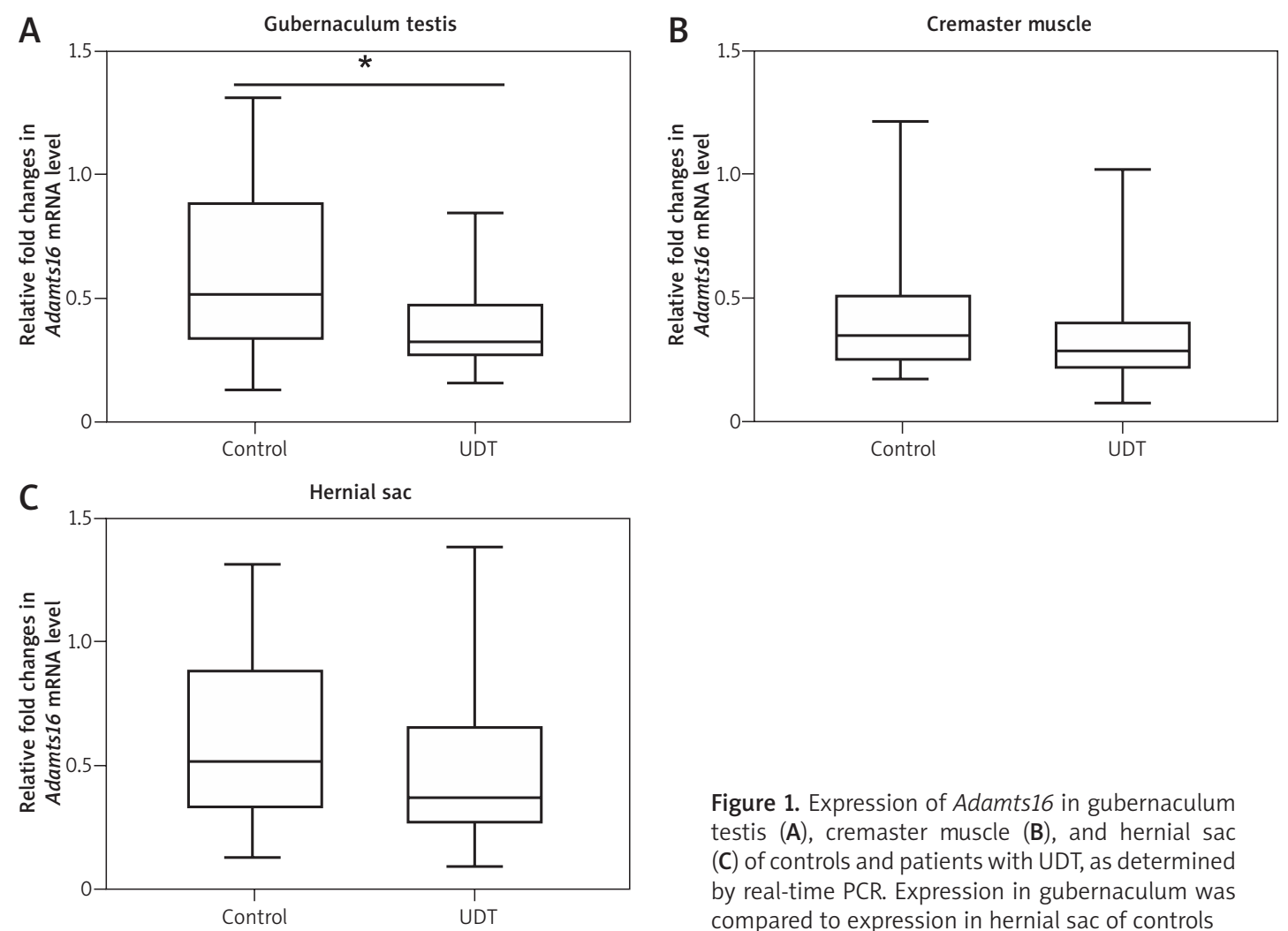

Figure 1. Expression of Adamts16 in gubernaculum testis (A), cremaster muscle (B), and hernial sac (C) of controls and patients with UDT, as determined by real-time PCR. Expression in gubernaculum was compared to expression in hernial sac of controls
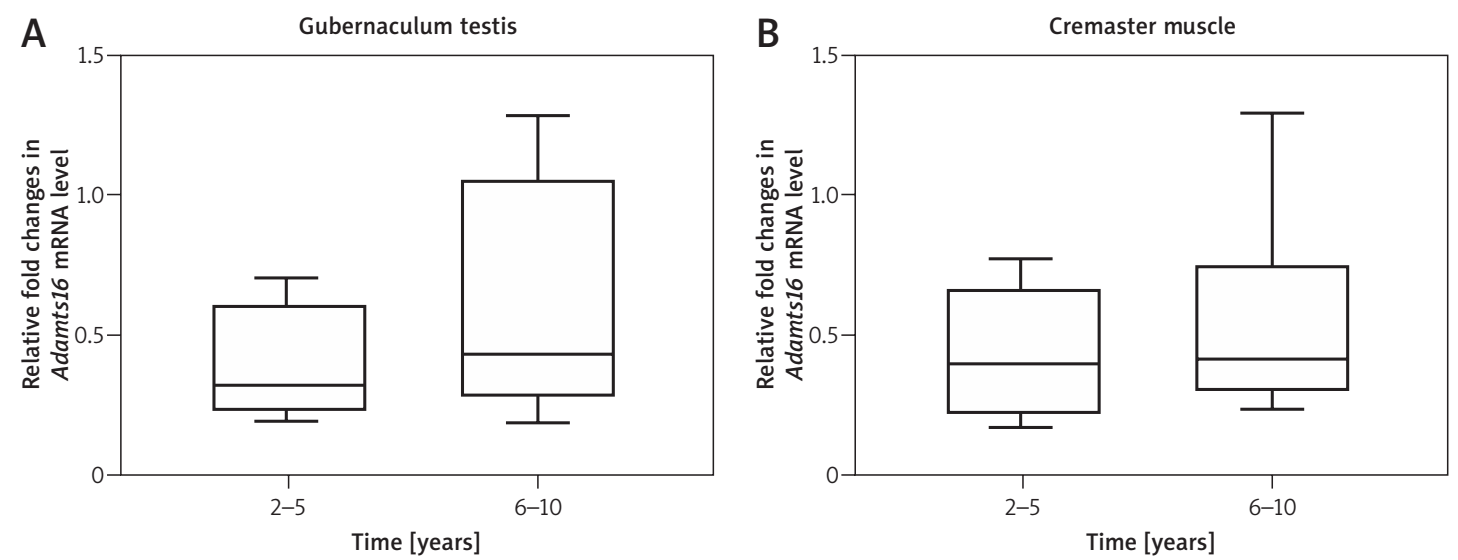

Figure 2. Expression of Adamts16 in gubernaculum testis (A), cremaster muscle (B) in patients with cryptorchidism, as determined by real-time PCR. Expression in hernia sac was not shown due to statistical insignificance

Table I. Distribution of genotypes, allele frequencies, and analysis of the odds ratio (OR) for rs16875054 A/G polymorphism of Adamts16 gene in UDT patients and controls

\begin{tabular}{|lcccccc|}
\hline Genotype/allele & $\begin{array}{c}\text { UDT patients } \\
(n=158)\end{array}$ & Freq. & $\begin{array}{c}\text { Controls } \\
(n=120)\end{array}$ & Freq. & OR & $P$-value \\
\hline A/A & 17 & 0.11 & 4 & 4 & $3.4831(1.1384-10.6566)$ & 0.02 \\
\hline A/G & 8 & 0.05 & 7 & 7 & $0.9366(0.3292-2.6646)$ & 0.89 \\
\hline G/G & 133 & 0.84 & 109 & 109 & Ref. \\
\hline A & 42 & 0.13 & 15 & 15 & $2.2993(1.2426-4.2544)$ & 0.007 \\
\hline G & 274 & 0.87 & 225 & 225 & Ref. \\
\hline
\end{tabular}

Genotype distribution in Hardy-Weinberg equilibrium; $\chi^{2} p<0.05$. 
the control group, respectively, while the genotype distribution was $66 \%$ for TT, $33 \%$ for G/T and $1 \%$ for GG for patients with cryptorchidism and 69\% for TT, $28 \%$ for G/T and 3\% for GG for the controls. The final analysis did not show a significant association of polymorphism with the risk of cryptorchidism.

Tables III and IV show the results of the distribution of rs16875122 G/T and rs58353460 A/G polymorphisms of the Adamts16 gene and their influence and correlation with cryptorchidism occurrence. Despite the conducted genotyping, in both cases correlation with the modulation of the risk of cryptorchidism was not observed. These data confirmed lack of any interdependence of rs16875122 $\mathrm{G} / \mathrm{T}$ and rs58353460 A/G polymorphisms of the Adamts16 gene with cryptorchidism presence in the Caucasian population.

\section{Discussion}

Metalloproteinases have commanded huge attention due to their role in a variety of normal and pathological conditions. Recent findings indicate that members of the ADAMTS family (a Disintegrin And Metalloproteinase with ThromboSpondin motifs) are also critically involved in morphogenesis [16]. Most of the ADAMTS proteases remodel extracellular matrix, or shed various proteins such as cytokines, adhesion ligands, growth factors, and their receptors [20].

Studies in recent years have indicated the physiological importance of ADAMTS in a variety of organ systems. However, there are still some ADAMTS members whose mechanisms and regulatory impact are still not fully elucidated.

Table II. Distribution of genotypes, allele frequencies, and analysis of the odds ratio (OR) for rs16875319 G/T polymorphism of Adamts16 gene in UDT patients and controls

\begin{tabular}{|lcccccc|}
\hline Genotype/allele & $\begin{array}{c}\text { UDT patients } \\
(n=158)\end{array}$ & Freq. & $\begin{array}{c}\text { Controls } \\
(n=123)\end{array}$ & Freq. & OR & $P$-value \\
\hline G/G & 2 & 2 & 3 & 0.03 & $0.5449(0.089-3.3362)$ & $<0.01$ \\
\hline G/T & 52 & 52 & 35 & 0.28 & $1.2143(0.7252-2.0334)$ & 0.46 \\
\hline T/T & 104 & 104 & 85 & 0.69 & Ref. & - \\
\hline G & 56 & 56 & 41 & 0.17 & $1.0769(0.6918-1.6763)$ & 0.74 \\
\hline T & 260 & 260 & 205 & 0.83 & Ref. & - \\
\hline
\end{tabular}

Genotype distribution in Hardy-Weinberg equilibrium; $\chi^{2}=0.787$.

Table III. Distribution of genotypes, allele frequencies, and analysis of the odds ratio (OR) for rs16875122 G/T polymorphism of Adamts16 gene in UDT patients and controls

\begin{tabular}{|c|c|c|c|c|c|c|}
\hline Genotype/allele & $\begin{array}{l}\text { Patients } \\
(n=158)\end{array}$ & Freq. & $\begin{array}{l}\text { Controls } \\
(n=121)\end{array}$ & Freq. & OR & $P$-value \\
\hline $\mathrm{T} / \mathrm{T}$ & 0 & 0.0 & 0 & 0.0 & - & - \\
\hline $\mathrm{G} / \mathrm{T}$ & 0 & 0.0 & 0 & 0.0 & - & - \\
\hline GG & 158 & 1.0 & 121 & 1.0 & Ref. & - \\
\hline $\mathrm{T}$ & 0 & 0 & 0 & 1.0 & - & - \\
\hline G & 316 & 1.0 & 242 & 1.0 & Ref. & - \\
\hline
\end{tabular}

Table IV. Distribution of genotypes, allele frequencies, and analysis of the odds ratio (OR) for rs58353460 A/G polymorphism of Adamts16 gene in UDT patients and controls

\begin{tabular}{|c|c|c|c|c|c|c|}
\hline Genotype/allele & $\begin{array}{l}\text { Patients } \\
(n=158)\end{array}$ & Freq. & $\begin{array}{l}\text { Controls } \\
(n=123)\end{array}$ & Freq. & OR & $P$-value \\
\hline $\mathrm{G} / \mathrm{G}$ & 1 & 0.006 & 0 & 0.0 & - & - \\
\hline$A / G$ & 0 & 0.0 & 0 & 0.0 & - & - \\
\hline $\mathrm{A} / \mathrm{A}$ & 157 & 0.994 & 123 & 1.0 & Ref. & - \\
\hline G & 2 & 0.006 & 0 & 0.0 & - & - \\
\hline$A$ & 314 & 0.994 & 246 & 1.0 & Ref. & - \\
\hline
\end{tabular}


One poorly characterized example, lacking knowledge of substrates and the molecular pathways in which it participates, is ADAMTS16. Still it was reported that its expression is essential in rodent fetal lung and kidneys, adult brain, and most recently, in rodent gonadal development $[6,21,22]$. Additionally, ADAMTS16 is linked with urgency urinary incontinence in women [23], functional impairment in schizophrenia [24] and hypertension (rats) [25].

In order to verify whether AdamtsS16 is implicated in testis descent, we performed RT-qPCR to analyze its expression in patients with diagnosed cryptorchidism. The obtained data indicate that patients with undescended testis have significantly lower expression of Adamts16 (Figure 1). The biggest changes were observed in the gubernaculum, which remains the key structure for testicular descent in humans. After birth, the gubernaculum undergoes extensive remodeling of the extracellular matrix (ECM), which is achieved by a tight balance of metalloproteinases and their inhibitors [26]. Also, studies on animal models showed that ECM remodeling by matrix metalloproteinases around/in the gubernaculum is necessary for its migration through the inguinal fat [27], with special emphasis on metalloproteinase MT1-MMP and MMP2, which play an important role in spermatogenesis [27, 28].

Our data are also in line with data obtained by Abdul-Majeed et al., who observed that lack of Adamts16 is responsible for the occurrence of cryptorchidism and subsequent infertility in homozygous Adamts16 mutant male rats [6]. Moreover, previous studies conducted by Zhao et al. indicate that disturbance in Adamts20 expression in dog gubernaculum is linked with cryptorchidism occurrence [29]. Further, Dun et al. described Adamts 10 as being expressed during the later stages of mouse spermatogenesis and suggested it to be an important factor during fertilization [30].

In our opinion, the more frequent decreased level of Adamts16 expression in patients with cryptorchidism clearly indicates the indirect function of the ADAMTS16 protein in the process of testicular descent. The direct link remains unclear; however, considering the wide range of interactions of ADAMTS16 with other metzincin family proteins and a number of growth factors, cytokines and signaling molecules processed by ADAMTS16, we postulate that the reduced expression level might affect the extracellular matrix remodeling and/or the mesenchymal cell migration. Consequently, it may lead to the disruption of gubernaculum elongation and to aberrant testicular descent.

Particular attention should be paid to the differences in expression found in our studies in patients depending on the age group. Previously mentioned studies highlight ADAMTS16 involvement in cryptorchidism and confirm data obtained from animal models. However, since ADAMTS16 is an important factor in morphogenesis [31], our discovery of the dependence of expression on age suggests that critical changes in ADAMTS16 activity and expression occur during prenatal development and shortly after birth. Additionally, taking into account further differences between age groups, not only in infants but also in children, we postulate that the level of expression depends on the hormonal balance of the organism and changes with mutation. Our findings are in line with one of the theories presented in the introduction to this article, which searches for the sources of cryptorchidism in hormonal disorders of the body or the interaction of these disorders with other environmental and genetic factors.

Since severe deficiency of the mRNA Adamts16 leads to a testis defect, we also investigated whether selected polymorphisms rs16875319, rs16875054, rs16875122, and rs58353460 in the Adamts16 gene correlate with occurrence of cryptorchidism.

Comparison of the genotype and allele frequencies for rs16875054 is shown in Table I. It shows that the $A / A$ genotype and $A$ allele may be responsible for increased risk of cryptorchidism. According to data shown in Table II, there is no evidence that rs16875319 polymorphisms in the Adamts16 gene is related to cryptorchidism. Despite the fact that our results show that rs16875319 and rs16875054 polymorphisms in the Adamts16 gene are not a major determinant to develop cryptorchidism in the Caucasian population, it cannot be excluded in other populations. Our results also confirmed that rs16875122 and rs58353460 polymorphisms do not occur in the Caucasian population (Tables III and IV). So far, many polymorphisms have been identified in the Adamts16 gene, but no research has been conducted on their modulation of the risk of cryptorchidism in the human model. Although most of the polymorphisms we studied did not show any relation to cryptorchidism, the results obtained for rs16875054 indicate that differences in structure may translate into effectiveness of action and, consequently, lead to the underlying cause of the disease. Probably the mechanism behind this process is very complex and involves more than one polymorphism, intergenic interactions, and interactions of the protein with other cellular factors. Therefore, in our opinion, further research in this field is necessary to better understand the role of the influence of Adamsts16 polymorphisms on the level of its activity and, consequently, on the potential impact on cryptorchidism development.

There is a long list of putative risk factors associated with cryptorchidism. The present study 
extends this list with a disturbance in Adamts16 expression.

Taking into consideration the above-mentioned points, it seems especially interesting to focus future research on ADAMTS16 involvement in cryptorchidism development.

\section{Acknowledgments}

This study was supported by departmental sources of the Medical University of Lodz, grant number 503/5-108-05/503-51-001-19-00.

We would like to thank Kinga Balińska, Damian Wilk and Krzysztof Olesiejuk for help and support during experiments which they provided, and Bartosz Mucha for professional advice and assistance.

\section{Conflict of interest}

The authors declare no conflict of interest.

\section{References}

1. Niedzielski J, Oszukowska E, Słowikowska-Hilczer J. Undescended testis - current trends and guidelines: review of the literature. Arch Med Sci 2016; 12: 667-77.

2. Leslie SW, Sajjad H, Villanueva CA. Cryptorchidism. Treasure Island (FL): StatPearls Publishing LLC. 2020.

3. Braga LH, Lorenzo AJ. Cryptorchidism: a practical review for all community healthcare providers. Canad Urol Assoc J 2017; 1-2 Suppl 1: 26-32.

4. Urh K, Kolenc Z, Hrovat M, Svet L, Dovč P, Kunej T. Molecular mechanisms of syndromic cryptorchidism: data synthesis of 50 studies and visualization of gene-disease network. Front Endocrinol 2018; 9: 425-35.

5. Ivell R, Hartung S. The molecular basis of cryptorchidism. Mol Hum Reprod 2003; 9: 175-81.

6. Abdul-Majeed S, Mell B, Nauli SM, Joe B. Cryptorchidism and infertility in rats with targeted disruption of the Adamts16 locus. PLoS One 2014; 9: e100967.

7. Liu Y, Min D, Bolton T, et al. Increased matrix metalloproteinases-9 predicts poor wound healing in diabetic foot ulcers. Diabetes Care 2009; 32: 117-9.

8. Aplin AC, Zhu WH, Fogel E, Nicosia RF. Vascular regression and survival are differentially regulated by MT1MMP and TIMPs in the aortic ring model of angiogenesis. Am J Physiol Cell Physiol 2009; 297: C471-80.

9. Higa R, Kurtz M, Capobianco E, Martinez N, White V, Jawerbaum A. Altered matrix metalloproteinases and tissue inhibitors if metalloproteinases in embryos from diabetic rats during early organogenesis. Reprod Toxicol 2011; 32: 449-62.

10. Nghia TVL, Xue M, Castelnoble LA, Jackson CJ. The dual personalities of matrix metalloproteinases in inflammation. Front Biosc 2007; 12: 1475-87.

11. Stevens LJ, Page-McCaw A. A secreted MMP is required for reepithelialisation during wound healing. Mol Biol Cell 2012; 23: 1068-79.

12. Ruiz V, Ordonez RM, Berumen J, et al. Inbalanced collagenases/TIMP-1 expression and epithelial apoptosis in experimental lung fibrosis. Am J Physiol Cell Physiol 2003; 285: L1026-36.

13. Yamashita CM, Dolgonos L, Zemans RL, et al. Matrix metalloproteinase 3 is a mediator of pulmonary fibrosis. Am J Pathol 2011; 179: 1733-45.
14. Dev K, Frank L. Expression of ADAMs (a disintegrin and metalloproteases) and TIMP-3 (tissue inhibitor of metalloproteinase-3) in human prostatic adenocarcinomas. Int J Oncol 2003; 23: 1365-71.

15. Nagase H, Visse R, Murphy G. Structure and function of matrix metalloproteinases and TIMPs. Cardiovasc Res 2006; 69: 562-73.

16. Trojanek J. Metaloproteinazy macierzy zewnątrzkomórkowej i ich tkankowe inhibitory. Postep Biochem 2015; 61: 356-63.

17. Groblewska M, Tycińska A, Mroczko B, Musiał W, Szmitkowski M. Metaloproteinazy macierzy zewnątrzkomórkowej w chorobach układu krążenia. Pol Merk Lek 2011; 178: 235-40.

18. Mead TJ, Apte SS. ADAMTS proteins in human disorders. Matrix Biol 2018; 71-72: 225-39.

19. Saran K, Nithya R, Ruowen. Emerging roles of ADAMTSs in angiogenesis and cancer. Cancers 2012; 4: 1252-99.

20. Bonnans C, Chou J, Werb Z. Remodelling the extracellular matrix in development and disease. Nature reviews. Mol Cell Biol 2014; 15: 786-801.

21. Gao S, De Geyter C, Kossowska K, Zhang H. FSH stimulates the expression of the ADAMTS-16 protease in mature human ovarian follicles. Mol Hum Reprod 2007; 13: 465-71.

22. Jacobi CL, Rudigier LJ, Scholz H, Kirschner KM. Transcriptional regulation by the Wilms tumor protein, Wt1, suggests a role of the metalloproteinase Adamts16 in murine genitourinary development. J Biol Chem 2013; 288: 18811-24.

23. Richter HE, Whitehead N, Arya L, et al. Genetic contributions to urgency urinary incontinence in women. J Urol 2015; 193: 2020-7.

24. McGrath LM, Cornelis MC, Lee PH, et al. Genetic predictors of risk and resilience in psychiatric disorders: a cross-disorder genome-wide association study of functional impairment in major depressive disorder, bipolar disorder, and schizophrenia. Am J Med Genet B Neuropsychiatr Genet 2013; 162B: 779-88.

25. Joe B, Saad Y, Dhindaw S, et al. Positional identification of variants of Adamts 16 linked to inherited hypertension. Hum Mol Genet 2009; 18: 2825-38.

26. Churchill JA, Buraundi S, Farmer PJ, et al. Gubernaculum as icebreaker: do matrix metalloproteinases in rodent gubernaculum and inguinal fat pad permit testicular descent? J Pediatr Surg 2011; 46: 2353-7.

27. Chen N, Harisis GN, Farmer P, et al. Gone with the Wnt: the canonical Wnt signaling axis is present and androgen dependent in the rodent gubernaculum. J Pediatr Surg 2011; 46: 2363-9.

28. Costa WS, Sampaio FJ, Favorito LA, Cardoso LE. Testicular migration: remodeling of connective tissue and muscle cells in human gubernaculum testis. J Urol 2002; 167: 2171-76.

29. Zhao X, Onteru S, Saatchi M, Garrick D, Rothschild M. A genome-wide association study for canine cryptorchidism in Siberian Huskies. J Anim Breed Genet 2014; 131: 202-9.

30. Dun MD, Anderson AL, Bromfield EG, et al. Investigation of the expression and functional significance of the novel mouse sperm protein, a disintegrin and metalloprotease with thrombospondin type 1 motifs number 10 (ADAMTS10). Int J Androl 2012; 35: 572-89.

31. Schnellmann R, Sack R, Hess D, et al. A selective extracellular matrix proteomics approach identifies fibronectin proteolysis by a disintegrin-like and metalloprotease domain with thrombospondin type 1 motifs (ADAMTS16) and its impact on spheroid morphogenesis. Mol Cell Proteom 2018; 17: 1410-25. 